Referencia para citar este artículo: Cárdenas, C. \& Pérez, C. (2017). Representación mediática de la acción de protesta juvenil: la capucha como metáfora. Revista Latinoamericana de Ciencias Sociales, Niñez y Juventud, 15 (2), pp. 1067-1084. DOI:10.11600/1692715x.1521814092016

\title{
Representación mediática de la acción de protesta juvenil: la capucha como metáfora*
}

\author{
CAMILA CARDENAS ${ }^{* * *}$ \\ Profesora Universidad Pompeu Fabra, España. \\ CAROLINA PÉREZ ${ }^{* * *}$ \\ Universidad de Lancaster, Inglaterra.
}

\section{Artículo recibido en septiembre 14 de 2016; artículo aceptado en diciembre 12 de 2016 (Eds.)}

- Resumen (analítico): este estudio muestra cómo un reportaje televisivo construye a los estudiantes como actores inherentemente agresivos y socialmente desviados, retratándolos como responsables de la colocación de una bomba en una estación de metro en Santiago (Chile) el año 2014. Se aborda la figura del 'encapuchado' como representante de la juventud movilizada, la cual es sistemáticamente marginalizada y excluida de la esfera pública en el relato periodístico. Las metodologías provienen de los Estudios Críticos del Discurso, a partir de las cuales tanto el texto como las imágenes se analizaron en relación con la recontextualización de acciones y motivaciones en la estructura narrativa. Los resultados sugieren que el joven encapuchado se utiliza metafóricamente para deslegitimar al movimiento estudiantil en su conjunto. También se destacan contribuciones interdisciplinarias al campo de los Estudios de Juventud.

Palabras clave: juventud, movimiento de protesta, movimiento estudiantil, Chile, medios de comunicación, reportaje, narración, discurso, semiótica (Tesauro de Ciencias Sociales de la Unesco).

\section{Media representations of youth protests: The hood as a metaphor}

- Abstract (analytical): This study aims to demonstrate how one particular television report constructs an image of students as inherently aggressive and socially deviant social actors, portraying them as the ones responsible for the placement of a bomb in an underground station in Santiago (Chile) in 2014. The authors approach the figure of the hooded demonstrator ('encapuchado') as representative of mobilized youth, who are systematically marginalized and excluded from the public sphere through the news story. Methodologies from Critical Discourse Studies are used in the study, in which textual and visual modes of discourse are analyzed in relation to the recontextualization of actions and motives included in the narrative structure. Results suggest that young hooded students are metaphorically used to delegitimize the student movement as a whole, actively contributing to the interdisciplinary field of Youth Studies.

Este artículo de investigación científica y tecnológica se deriva del cruce de las investigaciones doctorales de las autoras, ambas financiadas por el Programa de Formación de Capital Humano Avanzado de la Comisión Nacional de Investigación Científica y Tecnológica (Conicyt), mediante la Beca de Doctorado en el Extranjero Becas Chile Investigación Folio No 72130323, septiembre de 2012 a septiembre de 2016 (Camila Cárdenas); Investigación Folio No 72130132, septiembre de 2013 a septiembre de 2017 (Carolina Pérez), respectivamente. Los nombres de las investigaciones son: "Representación de la acción política juvenil en redes sociales: Análisis crítico de los discursos producidos en el grupo de Facebook 'Universitario Informado’ durante las movilizaciones estudiantiles en Chile (2011-2013)” y “¿Por qué protestan? La construcción discursiva y atribuciones de motivación del movimiento estudiantil chileno (2011-2013) en la prensa nacional y grupos de discusión”. Área de conocimiento: Ciencias Sociales; subárea: Sociología.

** Profesora de Lenguaje y Comunicación y Magíster en Comunicación (Universidad Austral de Chile), Doctora $($ en Traducción y Ciencias del Lenguaje (Universidad Pompeu Fabra, España). Orcid: 0000-0002-1842-7200. Índice H5: 5. Correo electrónico: camila.cardenas.neira@gmail.com

*** Licenciada en Letras, Mención Literatura y Lingüística Inglesa (Pontificia Universidad Católica de Chile), Magíster en Estudios del Discurso y Doctora (C) en Lingǘstica (Universidad de Lancaster, Inglaterra). Orcid: 0000-0002-1543-0797. Índice H5: 1. Correo electrónico: cperez. arredondo@gmail.com 
Key words: youth, protest movement, student movement, Chile, mass media, news flow, storytelling, discourse, semiotics (Social Sciences Unesco Thesaurus).

\section{Representação midiática da ação do protesto juvenil: $O$ capuz como metáfora}

- Resumo (analítico): Este estudo revela como uma reportagem televisiva constrói estudantes como atores sociais intrinsecamente agressivos e socialmente desviados, retratando-os como os responsáveis pela colocação de uma bomba em uma estação do metrô em Santiago (Chile) em 2014. Aproximamo-nos da figura do 'encapuzado' como representante da juventude mobilizada, sistematicamente marginalizada e excluída da esfera pública através da notícia. As metodologias estão ligadas aos Estudos Críticos de Discurso, do qual tanto o texto como as imagens foram analisadas em relação à recontextualização de ações e motivos na estrutura narrativa. Os resultados sugerem que os jovens encapuzados são usados metaforicamente para deslegitimar o movimento estudantil como um todo. Também são destacadas contribuições interdisciplinares para o campo dos Estudos da Juventude.

Palavras-chave: juventude, movimento de protesto, movimento estudantil, Chile, meios de comunicação, reportagem, narração, discurso, semiótica (Tesauro de Ciências Sociais da Unesco).

\section{-1. Introducción: la juventud bajo sospecha. -2. Marco teórico. -3. Metodología: enfoque discursivo-semiótico. -4 . Resultados. $-\mathbf{- 5}$. Conclusiones. -Lista de referencias.}

\section{Introducción: La juventud bajo sospecha}

El 8 de septiembre de 2014 tuvo lugar el estallido de una bomba en la estación de metro Escuela Militar, en Santiago de Chile ${ }^{1}$, causando importantes destrozos en infraestructura e hiriendo a 23 personas. Este acto, único en su tipo por realizarse de día y afectar un espacio con gran afluencia de público, fue catalogado como el más grave ataque terrorista ${ }^{2}$ ocurrido durante los últimos 20 años $^{3}$. De acuerdo a Villegas (2016), el tratamiento del terrorismo en la Constitución de 1980 -que rige desde la dictadura militar (1973-1990)- conduciría a la consagración de un mecanismo de protección represivo de la democracia, pues, en su origen, esta tipificación tuvo por finalidad confrontar la disidencia política ${ }^{4}$, lo que explicaría por qué

1 Más antecedentes en: https://es.wikipedia.org/wiki/Atentado de_Santiago_de_Chile_de_2014

2 La legislación penal vigente contempla el delito de colocación, envío, activación y detonación de artefacto explosivo en el marco de la Ley $\mathrm{N}^{\circ} 18.314$ o Ley Antiterrorista. Al respecto, ver Martínez (2015)

3 El Mercurio, 16 de agosto de 2015: http://impresa. elmercurio.com/Pages/NewsDetail.aspx? $\mathrm{dt}=16-08-2015 \% 20$ $0: 00: 00 \& \mathrm{New}$ I D $=339153 \& \mathrm{dt} \mathrm{B}=16-03-2017 \% 20$ 0:00:00\&Body $\mathrm{ID}=10 \&$ PaginaId $=8$

4 Esta ley establece penas que cierran los canales de participación política y ciudadana, vetando cualquier posibilidad de disenso ideológico. Tales inhabilitaciones son impedimentos para el esta ley "se ha aplicado en la última década a la criminalidad de indígenas y antisistémicos" ( $p$. 302). Dentro de este periodo, se han perpetrado unos 300 atentados de esta naturaleza, de los cuales más del 50\% apuntaría a grupos de carácter anarquista (Santibáñez, 2015), a pesar de que no siempre ha podido corroborarse esta vinculación en las pesquisas judiciales ${ }^{5}$.

En este contexto, la presente investigación se interesa por reconstruir la representación mediática de estos eventos, especialmente de las acciones y motivaciones de los sujetos juveniles involucrados. El reportaje televisivo que es objeto de análisis fue emitido por el noticiero Tele 13 de Canal $13^{6}$ el mismo día del incidente. En la sección de Reporteros se presentó la pieza audiovisual de 11 minutos y 17 segundos titulada "Radiografía a los colectivos

ejercicio de cargos o funciones públicas, tales como ser dirigente de organizaciones partidarias, vecinales, gremiales, estudiantiles, profesionales, empresariales o sindicales, explotar un medio de comunicación social, ser rector o director de establecimientos educativos o desempeñar labores de enseñanza, entre otras (Villegas, 2016).

5 Un caso emblemático de montaje judicial puede encontrarse en la investigación de Tamayo (2012).

6 Es un canal de televisión abierta de propiedad privada, cuya sociedad administradora está compuesta por la Pontificia Universidad Católica de Chile y el Grupo Luksic, consorcio empresarial conocido por concentrar una de las mayores fortunas del país. 
estudiantiles"7, en la que se abordaba la adscripción de grupos radicales al movimiento estudiantil, y se les implicaba como presuntos autores del bombazo.

Este trabajo recibió más de 220 denuncias ante el Consejo Nacional de Televisión (CNTV) por alarmar a la población con sensacionalismo excesivo, incitar a la desinformación y atentar contra el pluralismo y la convivencia democrática ${ }^{8}$. Adicionalmente, tanto los académicos como los dirigentes universitarios entrevistados acusaron desconocer los verdaderos fines del trabajo periodístico, aportando comunicados en los que argumentaron falta de ética y tendenciosidad ${ }^{9}$. Este caso resultó altamente polémico no solo por las reacciones que suscitó entre especialistas y profesionales de la comunicación, organizaciones civiles y estudiantiles, además del amplio debate continuado en redes sociales, también sentó precedentes legislativos que permitieron endurecer las penas para esta clase de delitos, extremando las posiciones políticas del gobierno de Michelle Bachelet (2014-2018), y otorgando nuevas facultades a las policías y sus centrales de inteligencia.

A partir de estos antecedentes, se postula que el reportaje erige la figura del encapuchado como depositario de disfunciones y anomalías sociales (Cárdenas \& Pérez, 2016), en concordancia con un discurso ideológico que ha invisibilizado a la juventud chilena de posdictadura, promoviendo la negativización, la marginalización y el ocultamiento de su acción política (Cárdenas, 2011; 2012; 2014a). Si bien dentro de sus repertorios de protesta los colectivos estudiantiles no han exhibido modalidades contenciosas que pudiesen asimilarse con prácticas terroristas (Cárdenas, 2016a), sí se han estereotipado sus formas

7 Disponible en: https://www.youtube.com/watch?v=okA54GRhck\&t $=3 \mathrm{~s}$

8 El Mostrador, 12 de septiembre de 2014: http://www.elmostrador. cl/noticias/pais/2014/09/12/suman-y-siguen-ya-son-mas-de220-las-denuncias-en-contra-de-canal-13-por-reportaje-sobrebombazo/

9 El Dínamo, 10 de septiembre de 2014: http://www.eldinamo.cl/ pais/2014/09/10/ex-dirigentes-rechazan-reportaje-de-canal-13que-vincula-bombazos-con-movimiento-estudiantil/ de manifestación con base en este semblante delictivo, asociación que ha sido trabajada intensivamente por la prensa establecida ${ }^{10}$ (Pérez, 2012; 2016).

En el ámbito de los Estudios Críticos del Discurso (ECD), se asume que los medios de comunicación cuentan con una potencialidad innegable para materializar y poner en contacto diversas cogniciones sociales, instalando $y$ modificando los temas que adquieren o no más importancia o valor en la sociedad (Van Dijk, 1985; 1988; 1990). Por ello desempeñan un papel crucial en la reproducción de la hegemonía y el control sobre las mentes, las interacciones y los comportamientos de la audiencia (Van Dijk, 2009). Esta manipulación discursiva deriva en la construcción de sesgos o prejuicios sobre actores o acciones puntuales que, a su vez, pueden extenderse a conocimientos, opiniones y actitudes más transversales (Van Dijk, 1999; 2011a; 2012; 2016).

Sobre este hecho noticioso en específico se determinó que diversos periódicos exaltaron la gravedad y las consecuencias negativas del incidente, con miras a incentivar en los/ as lectores/as un sentimiento de inseguridad y rechazo hacia este ataque y sus operadores, mediante distintas estructuras léxicas, gramaticales y semánticas de agencialización y atribución. Este examen evidenció tres estrategias habituales de responsabilización: la individualización (dos y hombres y una mujer identificados con sus nombres y apellidos), la agrupación (grupos extremistas, células herméticas) y la generalización (sospechosos, detenidos) (Estay, Castro, Cayunao, González, González \& Mancilla, 2016). Sus autores mostraron, a grandes rasgos, cómo los medios oficiales estigmatizan a las minorías que se rebelan ante el poder y desestabilizan el statu $q u o$, promoviendo su descrédito y exclusión.

Este artículo intenta avanzar en una dirección afín, con el objetivo de averiguar

10 En Chile la industria informativa se halla monopolizada por las elites político-empresariales, una casta educada en una matriz capitalista y en un conservadurismo valórico (Sunkel \& Geoffroy, 2001), que incluye tanto a los propietarios de los medios como a sus avisadores publicitarios. Estas elites disponen un cerco ideológico-financiero que incomunica a los ciudadanos y constriñe el debate social. 
con mayor profundidad cuáles son los recursos verbales y visuales utilizados en el corpus para relacionar a los colectivos estudiantiles y antisistémicos. Primero se desarrolla una discusión teórica en torno a la dependencia que se establece entre medios y movimientos sociales. Luego se esclarece el diseño metodológico que adapta y combina modelos de análisis lingüístico y semiótico. Los resultados se ordenan en función de las secuencies narrativas $\mathrm{y}$ sus patrones de significación a un macro $\mathrm{y}$ micro nivel. Finalmente se apuntan algunas conclusiones prominentes, destacando posibles contribuciones al campo de los Estudios de Juventud.

\section{Marco teórico}

\subsection{Comunicar la protesta}

Es sabido que los movimientos sociales tienen entre sus tareas prioritarias la de construir marcos interpretativos sobre los cuales orientar sus repertorios de acción, aprovechar sus oportunidades políticas y conformar sus estructuras de participación (Snow, Rochford, Worden \& Benford, 1989; McAdam, McCarthy \& Zald, 1999; Benford \& Snow, 2000). Esta es una de las razones por las cuales sus actos y reivindicaciones toman la forma de representaciones sociales (Jodelet, 1985; Moscovici, 1985; Abric, 1996), con las cuales compiten y resisten por conseguir mayor y mejor influencia en el espacio público (Tarrow, 2011). Tales marcos se crean y transforman típicamente en coyunturas de oposición (Klandermans \& Goslinga, 1999), siendo uno de los aspectos centrales en disputa los modos como las prácticas discursivas traducen los conflictos de intereses entre activistas y autoridades (Snow, 2004).

Así, mientras los movimientos despliegan una retórica optimista que destaca el cambio social como algo urgente y deseable, las élites dominantes gestionan numerosos recursos materiales y simbólicos para imponer una retórica reactiva y normalizadora. Desde las conceptualizaciones clásicas de los esquemas de comunicación -la "aguja hipodérmica" (Lasswell, 1927), el "modelo psicosocial" (Maletzke, 1964), "la agenda setting" (McCombs \& Shaw, 1972), etc.- se ha señalado que los medios masivos regulan los procesos de producción informativa(selección, presentación y difusión) en favor de los poderosos. Esto se cumple especialmente a partir de la década de los 60, cuando la representación de la movilización juvenil se pone al centro de la conflictividad social (Cohen, 1972; 1973).

Entre las aproximaciones disponibles para abordar la cobertura de eventos contenciosos se priorizan dos perspectivas complementarias. El paradigma consensual (Cohen \& Young, 1973) propone tres estrategias sistemáticas: a) el par exageración-distorsión engloba noticias que subrayan hechos violentos y destructivos para desembocar en relatos criminalizantes; b) la predicción incorpora en dichos relatos una amenaza implícita que anticipa que lo sucedido, inevitablemente, volverá a ocurrir, y; c) la simbolización comporta dos mecanismos articulados, a saber, el uso de determinadas palabras (e. g. 'encapuchado') que deviene en la creación de cierto estatus (e.g. 'delincuente'), y el énfasis dado a atributos o posesiones (e.g. vestimenta, accesorios) que activan emociones $\mathrm{y}$ actitudes negativas.

El paradigma de la protesta (Boyle, McCluskey, McLeod \& Stein, 2005; McLeod, 2007) propone que el tratamiento periodístico forma un patrón repetido en varios escenarios, pues cuanto más se aleja un grupo del estado normativo, es más probable que la prensa persiga difamarlo. Con este propósito se recurre a: a) el enmarcado de noticias para resaltar la interpretación causal y la evaluación moral de los acontecimientos; b) la dependencia de fuentes oficiales para entregar historias acreditadas y con prestigio; c) la invocación de la opinión pública para dar cabida a las voces de los/as ciudadanos/as; d) la deslegitimación para eludir el contexto de las manifestaciones, y; e) la demonización para relevar sus coacciones y consecuencias nocivas. 
Dado que los discursos mediáticos se constituyen a partir del uso de factualidades como formas de describir y objetivar el mundo, a menudo configuran hechos funcionales a unas narrativas que aseguran la naturalización de las realidades construidas (Del Valle, Mayorga \& Nitrihual, 2010). Por ello los medios son más susceptibles a la guionización y dramatización de la acción de los movimientos (Gamson, 1989), presentándolos como esencialmente efímeros y circunstanciales, más que como el resultado de desigualdades históricamente estructuradas y continuadas (Murdock, 1973).

\subsection{El caso chileno}

Desde hace más de una década (20062016), los/as jóvenes chilenos/as han venido denunciando las dinámicas de inequidad y segregación cimentadas y fomentadas por la educación de mercado en todos sus niveles, extendiendo sus efectos a los demás ámbitos sociales donde se expresan diferentes tipos y grados de precarización (Cabalin, 2012; Bellei \& Cabalin, 2013; Bellei, Cabalin \& Orellana, 2014). En este sentido, el movimiento estudiantil juega un rol trascendental en la repolitización de lo público (Cárdenas, 2014b), lo que significa que los modos de socialización e interacción juvenil conforman registros de politicidad que se activan cuando imperativos éticos así lo proponen (Portillo, Urteaga, González, Aguilera \& Feixa, 2012): la demanda por una educación pública y gratuita, laica y no sexista es apenas el comienzo de un camino que con el paso de los años apunta a la nacionalización de los recursos naturales, la implementación de una asamblea constituyente o la creación de una nueva fuerza política, entre otras modificaciones estructurales.

Según Aguilera (2008), "el tratamiento otorgado por los medios (...) alas movilizaciones estudiantiles no puede ser aislado de los modos generales con que la sociedad enfrenta las relaciones comunicativas con las juventudes, y se enmarca en (...) las formas de visibilizar a los jóvenes y en el esfuerzo que estos desarrollan por mostrar (...) su propio accionar" (p. 57). Esta representación mediática sigue dos ejes globales: a) la juventud debe ser obediente, verifica el sometimiento sociocultural a las normas y valores que la sociedad adultocéntrica les impone, y; b) la juventud no tiene voz, corrobora que estos actores no logran constituirse en sujetos del y de discurso, y en su lugar se les clasifica o cosifica (Aguilera, 2010), desconociendo su condición de interlocutores/ as legítimos/as (Cárdenas, 2016b).

En esta dirección, Condeza (2005) constata, por ejemplo, que en los noticieros de televisión los/as jóvenes son representados/ as básicamente como personas receptoras de situaciones externas o decididas por otros. Esta autora muestra que su posibilidad de entrar en pauta depende del grado de dramatismo del hecho ocurrido. Por lo tanto, se confunde sensibilizar a la opinión pública con impactarla, lo que implica que ellos/as devienen en objetos noticiosos incidentales antes que en fuentes informativas reales. De forma similar, Antezana (2007) advierte que los/as jóvenes aparecen principalmente vinculados/as con notas de carácter policial, habitualmente ligados/as a actos de violencia y delincuencia. Esta autora observa la presencia mayoritaria de noticias de carácter sujeto-masivas en las que ellos/ as son retratados/as como una amenaza, en tanto "se hace referencia al actuar irracional $\mathrm{y}$ antisocial (...) especialmente en protestas (...), [dentro de] una turba que actúa en forma colectiva (...) [bajo la denominación genérica de] manifestantes, encapuchados" (p. 162).

En esta línea, una de las principales formas de figuración juvenil en los medios masivos se relaciona con el activismo estudiantil, el cual se encasilla, de forma totalizante, como accionar agresivo y vandálico, haciéndose primar la contabilidad del desastre y confinando su agencia a categorías polares (el delincuente/ buen joven, comprometido/subversivo, etc.) (Aguilera, 2008). Entre las características transversales de estas coberturas destacan: 1) la naturaleza generalizadora y parcial de las informaciones, con base en una construcción 
que desatiende los detalles, la diversidad y los contextos de participación estudiantil; 2) la presencia recurrente de mentiras y distorsiones de la realidad, en razón de la cual se muestra a los/as jóvenes movilizados/as como portadores/ as de vicios y animosidades, y; 3) el énfasis en los aspectos perjudiciales, especialmente cuando se trata de representarlos/as conformando grupos homogéneos, desviados y peligrosos (Muñoz, Durán \& Thayer, 2014). Con ello se verifica la producción sistemática de un discurso mediático ahistórico, autoritario, criminalizante y espectacularizado del movimiento y sus actores (Gascón, 2016), lo que ayudaría a exacerbar, entre otros aspectos, la aparente desorientación política de los/as estudiantes, la manipulación de partidos de izquierda y de otras corrientes extraparlamentarias y antisistémicas (Yez, 2007).

\section{Metodología: enfoque discursivo- semiótico}

Esta investigación se sitúa en los Estudios Críticos del Discurso (ECD) porque recogen premisas básicas en torno a la hegemonía de los medios de comunicación, el problema de la manipulación de la información y su uso como recurso de poder. Desde esta perspectiva, los fenómenos sociales son deconstruidos en términos ideológicos mediante el análisis de realizaciones lingüísticas y semióticas que se actualizan en contextos políticos, económicos y culturales concretos (Fairclough, 1995; Titscher, Meyer, Wodak \& Vetter, 2000; Van Leeuwen, 2008; Van Dijk, 2011b; Wodak, 2013). Cabe recalcar que los ECD no son un método unificado sino que constituyen un campo interdisciplinario y multimetodológico (Weiss \& Wodak, 2003; Fairclough, 2005; Wodak \& Meyer, 2009; Fairclough, Mulderrig \& Wodak, 2011; Van Dijk, 2015), en el que los modelos propios de los estudios discursivos, así como otros provenientes de las humanidades y las ciencias sociales, pueden ser integrados.

En el modelo considerado confluyen enfoques derivados de la Semiótica Social y la
Lingüística Sistémico-Funcional. Por un lado, se siguen las propuestas de representación visual de la metáfora (Feng \& O'Halloran, 2013a; Feng \& Espindola, 2013) y de prosodia emocional (Feng \& O'Halloran, 2013b; Feng \& Qi, 2014) para abordar la estructura narrativa del reportaje televisivo y averiguar cómo se representa a los/as jóvenes en sus fases, experiencias y evaluaciones recurrentes. Por otro lado, se recurre al enfoque de acción social (Van Leeuwen, 2007, 2008) para relevar cómo los diferentes modos semióticos configuran esta narración y esclarecer cómo las acciones y motivaciones juveniles son empleadas para deslegitimar al movimiento estudiantil en los discursos de los medios tradicionales. El análisis se ejecuta en dos niveles.

\subsection{Macro-análisis}

En el nivel macro se identifica y describe la estructura narrativa a partir de determinadas metáforas médicas que se desprenden de la noción de radiografía con la que se titula el reportaje. Tales metáforas darían continuidad a la historia a través de tres secuencias elementales: orientación, complicación y resolución. Para esto se trabaja con base en las tres metafunciones del lenguaje (Halliday \& Matthiessen, 2014), las cuales se vinculan, a grandes rasgos, con: 1) la experiencia humana del mundo (significado ideacional: s-ide), 2) los intercambios entre emisores y destinatarios (significado interpersonal: s-int), y; 3) la organización de cierta cantidad de contenidos (significado textual: s-tex). Dichos significados se instanciarían en virtud de las etapas, vivencias y sentimientos que recrea el relato periodístico, tal como se esquematiza en la Figura 1. 
Figura 1: Detalle de las categorías del macro-análisis y sus relaciones.

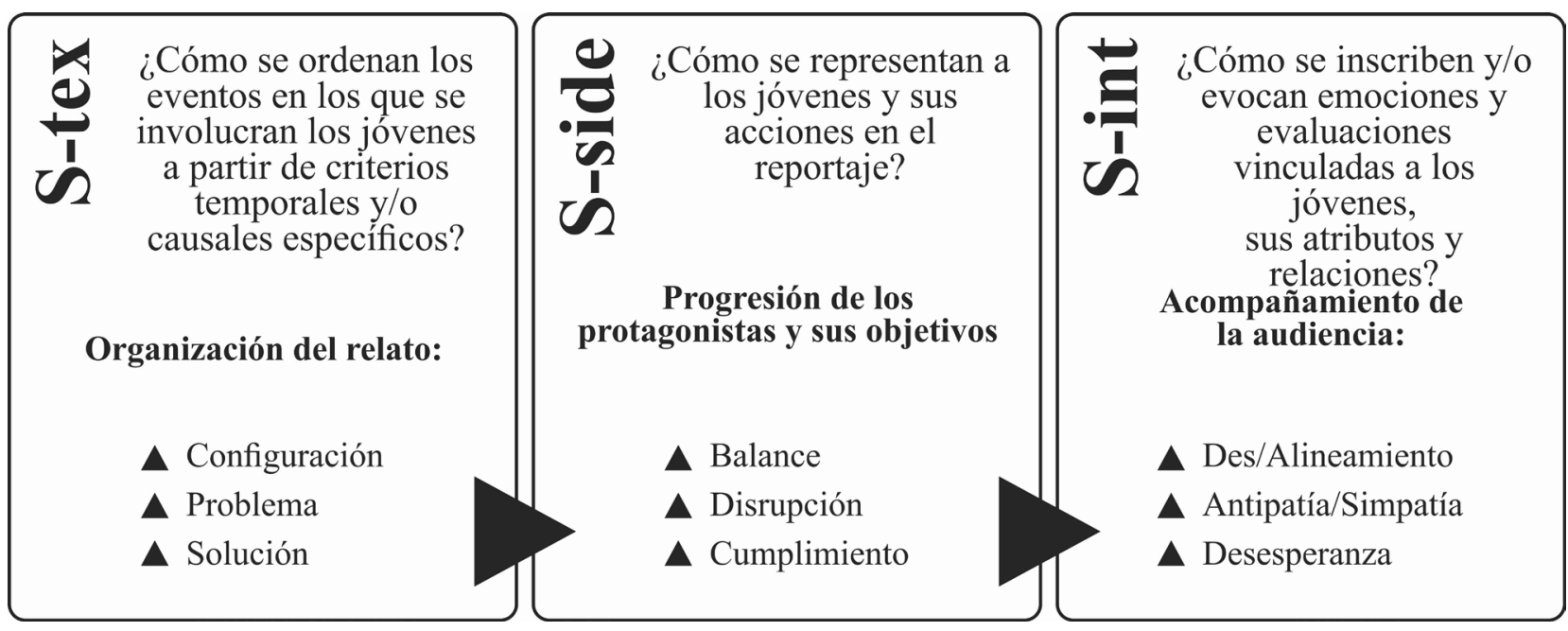

Fuente: elaboración propia.

Conviene destacar que aunque muchas de las categorías previstas son formuladas inicialmente por las teorías consultadas, estas han sido aplicadas a series y películas de ficción. Por ello, algunas de ellas se han mantenido y otras han sido levemente modificadas para atender la especificidad del género audiovisual analizado.

\subsection{Micro-análisis}

En el nivel micro se caracteriza y explica el funcionamiento de tres modos semióticos principales: verbal, visual y sonoro. En particular, se pone énfasis en la representación multimodal de los/as jóvenes en razón de: 1) las estrategias referenciales (cómo se les identifica); 2) las estrategias predicacionales (cuáles acciones se les atribuyen); 3) las estrategias de (re)contextualización (cómo son trasladados/as desde el contexto social al contexto informativo modelado por el reportaje), $\mathrm{y} ; 4)$ las estrategias de (des)legitimación (cómo son o no validados/as a través del relato periodístico). Si bien estas estrategias tienden a realizarse simultáneamente, es necesario establecer si estos modos semióticos aportan significados congruentes o incongruentes, vale decir, si los sentidos de los enunciados verbales, las imágenes y los sonidos son convergentes (co-contextualizados) o divergentes (recontextualizados) entre sí. La Figura 2 ilustra las cuatro dimensiones exploradas para reconstruir la relación de los encapuchados con el movimiento estudiantil. 
Figura 2: Detalle de las categorías del micro-análisis y sus relaciones.

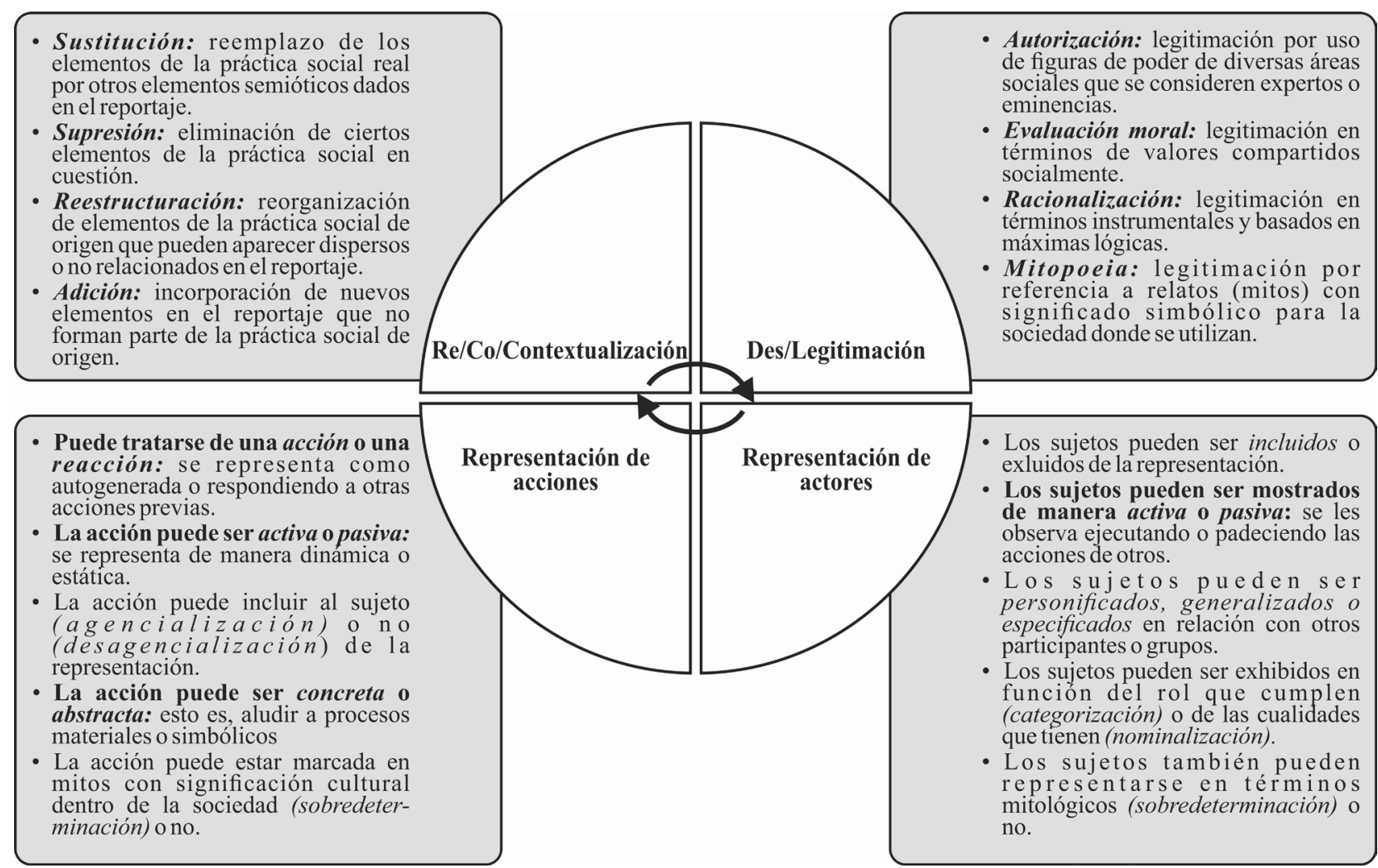

Fuente: elaboración propia.

Este modelo debiese ayudar a comprender cómo determinados patrones de representación multimodal fundamentan, dirigen y articulan el tratamiento mediático en términos narrativos, esto es, de acuerdo a secuencias consecutivas y funcionales que, a su vez, afectan las formas en que los/as jóvenes, sus actos y propósitos son retratados ante la audiencia. Con ello se espera demostrar la relación macro-micro del análisis y su potencial interpretativo.

\section{Resultados}

\subsection{Secuencia de orientación:} representación de la amenaza social

La secuencia de orientación (S-ORI) corresponde a la configuración del problema, y su objetivo consiste en constatar un estado de cosas que, pese a resultar anormal y peligroso, se muestra como familiar (s-tex). S-ORI establece una situación de balance con la cual se naturaliza a los participantes, eventos y circunstancias que suscitan un ambiente de conflictividad social permanente (s-ide). Con S-ORI se provoca en la audiencia la adopción de un posicionamiento ideológico en torno a los actores y procesos evaluados, esto es, deben alinearse o desalinearse con ellos de acuerdo a sus actitudes y conocimientos previos $(s-i n t)$. Es justamente sobre esta dimensión emocional y sociocognitiva donde el relato periodístico pretende impactar, con miras a reacomodar estos juicios y apreciaciones progresivamente.

En S-ORI se lleva a cabo una contextualización del problema con base en la incorporación de distintas voces: 1) la voz de la autoridad experta alude a dicho problema sugiriendo una metáfora teatral ("la escenificación del conflicto"), con la cual busca explicar esta modalidad de protesta desde una perspectiva teórica; 2) la voz de la autoridad policial introduce una de las principales motivaciones asignadas a los encapuchados, 
como es provocar daños a infraestructura y personal de carabineros; 3) las voces que representan al movimiento estudiantil también definen las motivaciones asignadas a los encapuchados pero en una dirección opuesta, a saber, sumarse a las reivindicaciones compartidas y reaccionar al dominio institucional, y; 4) la voz del periodista vincula la acción de los encapuchados a otros hechos punibles y los sindica como sospechosos del atentado explosivo.

En términos generales, S-ORI presenta a los participantes, sus acciones y fines con alto nivel de habitualidad y radicalización. En esta línea, se persigue un efecto de co-contextualización semiótica para recrear un contexto de amenaza social, el cual se delimita en primera instancia a través de recursos verbales (voz en off del periodista, GC en pantalla "DETRÁS DE LA CAPUCHA"), y se refuerza sistemáticamente

\section{Figura 3: Ejemplos S-ORI}

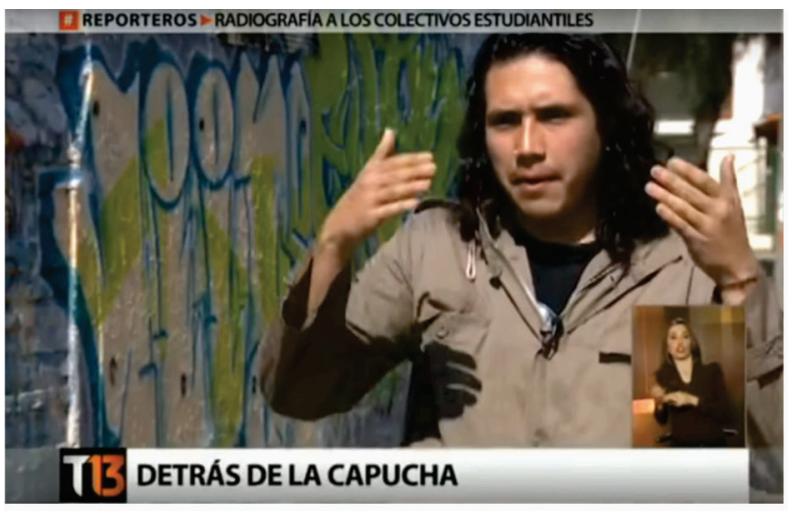

"Pero nosotros no negamos esa vía de manifestación. cachay, tampoco la asumimos públicamente como la vía del colectivo, cachay o la vía estudiantil para lograr los objetivos del movimiento estudiantil. Los cabros que eligen encapucharse, cachay, también aportan a la cachay, a la construcción, cachay, de este movimiento". (Entrevistado: Juan Vega, Colectivo "Vamos", min. 01.07-01-21).

Como se observa a la izquierda, con la intervención de Juan Vega se representa a los colectivos estudiantiles ("nosotros") mediante estrategias de agrupación e inclusión, y se les distingue de otros ("los cabros que eligen encapucharse") mediante estrategias de determinación y especificación. Las acciones acometidas son de un lado nominalizadas mediante recursos visuales (secuencias de imágenes de enfrentamientos entre encapuchados y policías y de las calles ocupadas con destrozos, fuego y gases lacrimógenos). Adicionalmente, se formulan evaluaciones a partir de la distinción general entre endogrupo (la sociedad) y exogrupo (encapuchados, anarquistas, radicales). Dado que las distintas voces introducen valoraciones disímiles, se tiende frecuentemente a la polarización ideológica como ya se anticipaba con $s$-int. De esta forma, tanto en el modo verbal como visual se incita la desalineación de la audiencia en relación con individuos, grupos y actos agresivos, $\mathrm{y}$, consecuentemente, se incentiva mayor alineación con quienes padecen sus efectos (los ciudadanos) y buscan reestablecer el orden vulnerado (fuerzas policiales). En la Figura 3 se destacan algunos ejemplos para dar cuenta de los patrones referidos.

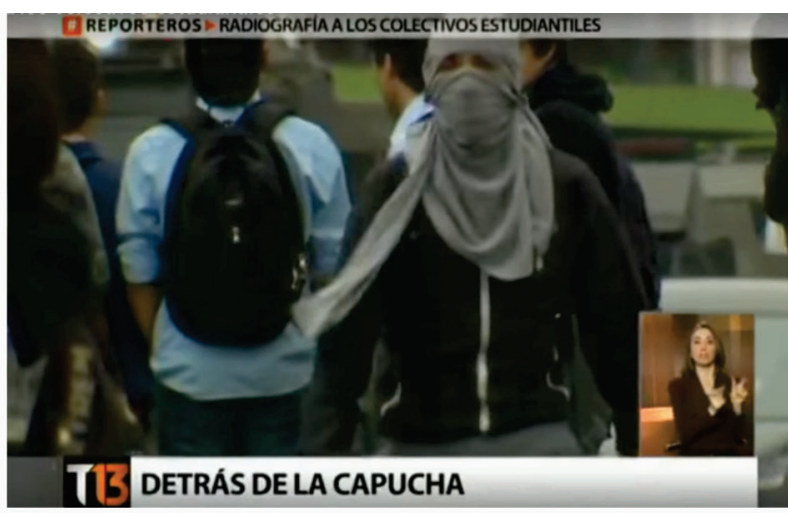

"Registramos el actuar de los denominados capuchas, la mayoría ligados a colectivos secundarios y universitarios del movimiento estudiantil: el escondite perfecto para la radicalización". (Voz en off periodista: Patricio Nunes, C13, min. 02.05-02.17).

("vía de manifestación") y del otro orientadas hacia propósitos volitivos y racionales (elegir, aportar), y en su conjunto son circunscritas dentro de una narrativa sobre la injusticia social, según la cual ciertos/as jóvenes deciden conscientemente protestar tras una capucha como parte de su lucha para restaurar un sistema democrático más igualitario ("Nosotros como 
colectivo más que todo entendemos que la violencia nace de... de una rabia generada por este sistema que violenta a las personas día a día". Entrevistado: Gonzalo Navarro, Colectivo "Acción Libertaria", min. 01.26-01.36).

Ahora bien, aunque estos fragmentos se incluyen con la intención aparente de dar cabida a las opiniones estudiantiles, con el trabajo de montaje audiovisual dicha búsqueda de legitimación entra en contradicción con las representaciones construidas por las imágenes que acompañan sus declaraciones, las que exhiben continuamente los ataques de encapuchados y sus secuelas en el espacio público, tal como se muestra a la derecha de la Figura 3. En este sentido, más que validarlos como sujetos del discurso, se busca tergiversar sus puntos de vista al subsumir la movilización estudiantil en un vandalismo generalizado. Esta vinculación es propuesta por el reportero a partir de estrategias de generalización y categorización de los antisociales ("los denominados capuchas"), cuya procedencia es cuantificada ("la mayoría") y ligada explícitamente a colectivos universitarios y secundarios, mediante una comparación ("el escondite perfecto") de connotaciones negativas.

Estas y otras realizaciones ayudan a construir tres metáforas médicas que otorgan coherencia simbólica a S-ORI: disfunción, diagnóstico, síntomas. Todas ellas dan cuenta de la detección de un comportamiento irregular (conflictivo, peligroso, destructivo) dentro de un cuerpo mayor (la sociedad). Aunque el foco de S-ORI está puesto en modelar estos actos anómalos y a sus responsables anónimos, la participación estudiantil puede recuperarse de las entrevistas mencionadas y de la repetición de algunas capturas que registran manifestaciones estudiantiles. Por consiguiente, estas metáforas no solo normalizan la acción disidente de encapuchados y grupos antisistémicos y el modo como esta afecta la seguridad y las reglas de la sociedad, sino que además estabilizan una asociación fundante entre juventud y amenaza, cuyo examen -radiografía- se presenta para ser inspeccionado por los/as televidentes.

\subsection{Secuencia de complicación: representación de la desviación juvenil}

La secuencia de complicación (S-COM) corresponde a la profundización del problema, y su objetivo consiste en caracterizar en detalle la composición, las formas de acción y funcionamiento, los escenarios, los recursos y las finalidades de los grupos que son el centro de la investigación (s-tex). S-COM busca enlazar directamente los actos y motivaciones de los encapuchados al movimiento estudiantil y sus modos de protesta y figuración pública (s-ide). Con ella también se aspira a inducir en la audiencia sentimientos de simpatía y antipatía en relación con los actores sociales evaluados, sus atributos y propósitos recurrentes, de acuerdo al esquema ideológico que se ha venido instalando desde la secuencia anterior $(s-i n t)$.

$\mathrm{S}-\mathrm{COM}$ se subdivide en seis etapas a partir de las cuales se realiza un examen exhaustivo de estas agrupaciones y sus criterios de identificación: 1) declaración de vínculos explícitos con el movimiento estudiantil; 2) definición de modus operandi; 3) estimación de repercusiones e impactos; 4) indagación de colectivos y casos concretos; 5) descripción de medios y tácticas de visibilización y coordinación, y; 6) revisión de procesos y sentencias judiciales recientes. Tales etapas habilitan la progresión del relato periodístico y la construcción de causalidad entre eventos que no necesariamente tienen una conexión lógica. Cada una persigue mostrar el actuar disruptivo de estos grupos en la sociedad, pero no así al interior del movimiento, procurando la indiferenciación de sus miembros y causas comunes, aun cuando los/as estudiantes han sostenido a lo largo del tiempo un discurso unificado para distinguirse continuamente de los encapuchados y sus prácticas.

En S-COM se despliegan cuatro mecanismos narrativos principales: a) la rutinización de los actos de violencia (marcados por un alto grado de automatización e indiferencia); b) la conformación de células profesionalizadas (las que operarían al alero de instituciones universitarias, beneficiando su pervivencia y reproducción); c) la estimación 
de daños a personal e infraestructura policial (como consecuencias típicas de las que sobresalen sus niveles de extremismo y sedición), y; d) la judicialización y condena pública (como corolario de un relato de advertencia: mitopoeia). En buena parte de ellos se recurre a una estrategia de cocontextualización semiótica donde el modo textual fija y modela la desviación juvenil como axioma social, mientras que el modo visual verifica y justifica dicho axioma con diversos registros (fotografías, vídeos, etc.) que servirían de evidencia.

Adicionalmente, se expresan valoraciones fundadas en la oposición nosotros (la sociedad) v/s ellos (los antisociales). Ciertas entidades (la ciudad, propiedad pública y privada, las fuerzas de orden, etc.) representan metonímicamente el cuerpo social que es objeto de ataque, activando diversas actitudes que reprueban a los individuos responsables de esta clase de coacción. Como contraparte, se promueven actitudes que fortalecen la defensa y la solidaridad interna para resistir y rechazar dicha amenaza. Con esto se exacerban los sentimientos de simpatía y antipatía que construyen una división moral y ética entre los participantes (capuchas, radicales, anarquistas v/s policías, ciudadanos). En la Figura 4 se destacan algunos ejemplos para dar cuenta de los patrones referidos.

Figura 4: Ejemplos S-COM
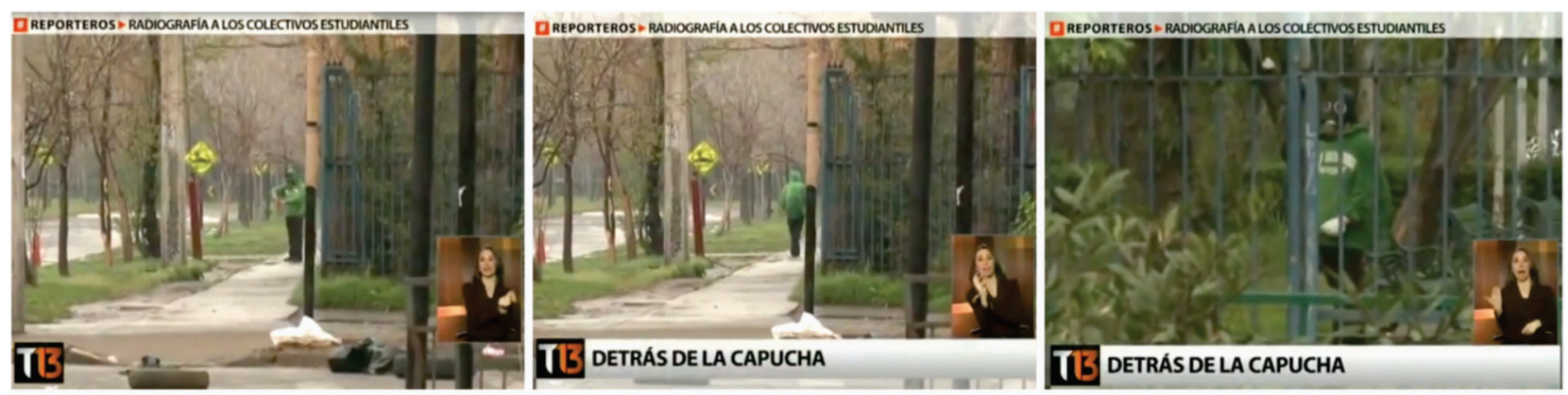

"Miércoles en la Facultad de Filosofía de la Universidad de Chile. Un grupo de encapuchados comienza los disturbios. Se mueven y esconden por rincones que conocen de memoria. Los desórdenes se dan entre el medio día y las cuatro de la tarde, nunca los viernes por temor a quedar detenidos todo el fin de semana. No son más de $\mathbf{3 0}$ máximo. Esta imagen corresponde a un encapuchado el martes. Al día siguiente aparece con la misma ropa para enfrentarse nuevamente a la policía." (Voz en off periodista: Patricio Nunes, C13, min. 02.47-02.52).

El reportero explica que los fotogramas se obtienen en distintos días aunque no haya forma de comprobarlo, además afirma que los encapuchados volvieron deliberadamente al mismo lugar para repetir los ataques, lo que no puede derivarse con certeza de las imágenes (el sujeto lleva puesta la misma ropa, lo que se aduciría como prueba). Esta maniobra de montaje puede conducir y/o potenciar interpretaciones sesgadas o estereotipadas por parte de la audiencia, basadas en una manipulación ostensible de los recursos semióticos empleados.

Existe una clara incongruencia entre los significados que aportan los modos verbal y visual en este fragmento. Verbalmente, los encapuchados son representados como actores agrupados y nominalizados, cuya motivación es acudir a la universidad para embestir a la policía, emprendiendo sus protestas en determinados días y horarios para evitar ir a prisión (actuar premeditado y entrenado). Mientras se señala que este manifestante se estaría preparando para enfrentarse con carabineros (propósito orientado a objetivos), estos aparecen luego como meros receptores de la agresión, la cual resulta, a su vez, categorizada por rutinización (actos típicos y predecibles).

Visualmente, el encapuchado se representa ejecutando una acción no transactiva (se encuentra de pie gran parte del tiempo sin interactuar con nadie), la que se configura a partir de dos tipos procesos: materiales como encender una bomba molotov, girar, caminar y alejarse, y de comportamiento como empinarse y mirar. La toma es lejana y 
la distancia es impersonal, lo que favorece la disociación de los/as televidentes. El encuadre se divide en dos para captar la calle y parte del campus universitario, asociación que enfatiza la adscripción de los grupos radicales a los colectivos estudiantiles.

Estas y otras realizaciones ayudan a construir tres metáforas médicas que otorgan coherencia simbólica a S-COM: invasión, contagio, padecimiento. Todas ellas dan cuenta de la irrupción de un cuerpo extraño al interior de un cuerpo mayor (el movimiento estudiantil). De esta manera, se confirma la propagación de conductas destructivas y dañinas propias de los encapuchados hacia las organizaciones juveniles, cuya acción resulta no solo frecuentemente generalizada, sino también objetivada como intrínsecamente maliciosa.

\subsection{Secuencia de resolución:} representación de la subversión estudiantil

La secuencia de resolución (S-RES) corresponde a la conclusión del problema, y su objetivo consiste en demostrar el enquistamiento de agrupaciones violentistas al interior del movimiento estudiantil (s-tex). Por tanto, S-RES busca corroborar la relación estructural existente entre los grupos investigados $\mathrm{y}$ los colectivos secundarios y universitarios planteada previamente (s-ide). Con ella se busca evocar en la audiencia un estado anímico de desesperanza, desmoralizante y desalentador respecto a las consecuencias sociales que supone desvelar el vínculo entre acción política juvenil y acción juvenil insurgente $(s-i n t)$.

S-RES se subdivide en cuatro etapas que disponen un examen más focalizado del movimiento y los colectivos que lo constituyen: 1) excepción de organismos estudiantiles no violentos; 2) conformación de colectivos estudiantiles durante las movilizaciones recientes (2006-2011); 3) ejemplificación de algunos colectivos estudiantiles, y; 4) evolución de los colectivos estudiantiles en general. A diferencia de S-COM, estas etapas parecen responder, en apariencia, a una orden más lógico y articulado, que permite hacer inferencias sobre los fundamentos, la trayectoria histórica del movimiento y su formación política.

En concordancia con lo anterior, son cuatro los aspectos que explicarían cómo los/as jóvenes se rebelan ante la autoridad policial y la institucionalidad gubernamental, convirtiéndolos en individuos que incentivarían la desestabilización social con base en distintas modalidades de resistencia: a) desmarcarse de las juventudes partidistas tradicionales; b) ascender en las jerarquías de poder; c) aumentar la representatividad en las bases, y; d) conquistar una "tercera vía" (presuntamente no bipartidista). Esta representación facilita la imbricación de grupos violentos y no violentos, implicándose el predominio de los primeros sobre los segundos.

En S-RES se valora la manera en que se produce un escalamiento de la insurrección juvenil. Así, la dependencia entre juventud y subversión social se expondría como ineludible, y sus secuelas como esencialmente perjudiciales. Esto se logra a partir de una estrategia de re-contextualización semiótica que consiste en alternar reiteradamente juicios positivos sobre el movimiento (capacidad de congregación y cohesión interna) en el modo verbal (intervenciones de expertos y dirigentes), con juicios negativos sobre los grupos radicales (imágenes de capuchas generando múltiples desmanes en plazas y avenidas) en el modo visual. En la Figura 5 se destacan algunos ejemplos para dar cuenta de los patrones referidos. 
Figura 5: Ejemplos S-RES

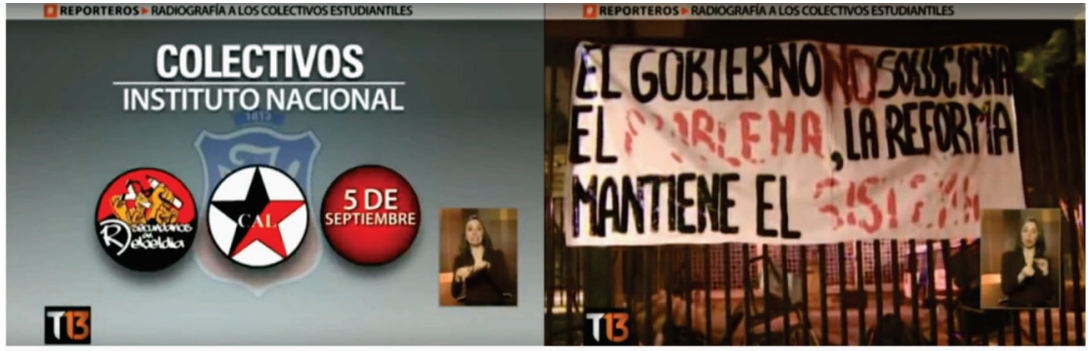

"En el Instituto Nacional existen tres, uno de ellos es el Colectivo de Acción Libertaria, grupo que fue decisivo en las tomas de mayo pasado". (Voz en off periodista: Patricio Nunes, C13, min. 09.31-09.39).

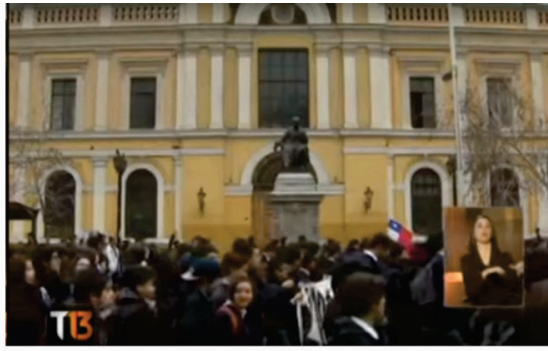

"Colectivos que buscan una tercera vía, una que hoy los posiciona como una voz de fuerza dentro del movimiento estudiantil". (Voz en off periodista: Patricio Nunes, C13, min. 11.05-11.17).
Con este trabajo de enmarcado se procede a la tipificación de colectivos de inspiración anarquista en tres colegios emblemáticos de Santiago, los cuales son individualizados (nombre completo y logo) en una presentación gráfica, cuestión que colabora en su categorización y eventual estigmatización. En el caso del Instituto Nacional, se resalta el rol influyente del "Colectivo Acción Libertaria" en las movilizaciones pasadas, y se recuperan imágenes de archivo de alguna de las tomas del liceo con el fin de afianzar el sentido de radicalización atribuido anteriormente a la protesta estudiantil.

La secuencia continúa con una serie de entrevistas a dirigentes que buscan desligarse de las acciones y motivaciones que se arrogan a los encapuchados. Esta auto-representación contempla que sus manifestaciones tienden a ser consideradas inherentemente violentas por las autoridades, pero proponen que modalidades contenciosas como ocupaciones o paralizaciones no cabrían dentro de esta clasificación, relegitimándolas como acciones consensuadas por sus bases ("Si bien nosotros no participamos en actos de violencia, siempre se está como... en la... en la disyuntiva entre como... apoyar o no apoyar (...) qué tan válido puede llegar a ser un acto, no de violencia obviamente como tirar una molotov o algo así, pero un acto como... por ejemplo un paro, una toma que según algunos son actos de violencia". Entrevistado: Diego Medina, Colectivo "Acción Libertaria", min. 10.02-10.10).

En los minutos finales se intercalan imágenes de confrontaciones entre carabineros y grupos de encapuchados, por un lado, y de marchas masivas y pacíficas, por el otro. Como se aprecia en el tercer fotograma, mientras el periodista subraya el papel adquirido por los colectivos anarquistas dentro del movimiento estudiantil y los posiciona como agentes dominantes, se muestran varias columnas de estudiantes que exacerban su homogenización y crecimiento desmedido.

Estas y otras realizaciones ayudan a construir tres metáforas médicas que otorgan coherencia simbólica a S-RES: colapso, metástasis, propagación. Todas ellas dan cuenta de la diseminación de un cuerpo extraño dentro de un cuerpo mayor (el movimiento estudiantil primero, y la sociedad en su conjunto después). De este modo, no solo se concreta la representación de una intrusión violentista que avanza peligrosamente al amparo de las juventudes movilizadas, cuyo carácter subversivo resulta ser inseparable de sus formas de acción y visibilización pública, sino que además se confirma la premisa del reportaje, en razón de la cual el propio movimiento constituiría un mal que está afectando al país entero.

\section{Conclusiones}

Del macro-análisis es posible sintetizar que las metáforas médicas resultan congruentes y consistentes a lo largo de las distintas secuencias y etapas de la estructura narrativa. Con ellas se trabaja la asociación de los encapuchados con 
los colectivos estudiantiles en tanto organismos cuya interacción afecta a un cuerpo mayor como es la sociedad. En este sentido, la orientación, la complicación y la resolución del problema investigado reenmarcan continuamente los estados de detección, irrupción y diseminación de la enfermedad que atacaría al país. Por ello, la radiografía propuesta por el reportaje desempeña una función cautelar en la que los medios operan como censores de la realidad nacional que prescriben. Adicionalmente, estas metáforas se desarrollan mediante la articulación de significados ideacionales, interpersonales y textuales que tornan inteligible la identificación de los/as jóvenes y sus propósitos antisociales, las emociones de inseguridad, temor $y$ reprobación que se desprenden de estos sujetos y sus comportamientos típicos, y las posibles implicancias y repercusiones perjudiciales derivadas de dicha relación, respectivamente.

Del micro-análisis se puede resumir que, en cuanto a la representación de actores, términos como encapuchados, capuchas, anarquistas y radicales son usados indistintamente para referirse a participantes de manifestaciones secundarias y universitarias y/o pertenecientes a establecimientos educacionales. Esto se hace más evidente en el modo visual, en donde las secuencias de imágenes que registran la confrontación entre los encapuchados y la policía se intercalan con aquellas que asocian sus modos de actuación a espacios y prácticas propias del mundo estudiantil, propiciando la activación de valoraciones negativas y asociaciones estereotipadas en la audiencia. En cuanto a la representación de acciones, nominalizaciones como ataques, protestas y manifestaciones son usadas de manera abstracta para potenciar en los/as espectadores/ as la incorporación de preconcepciones y prejuicios alrededor del significado social del encapuchado y sus variantes referenciales.

Estos resultados sugieren que el joven encapuchado, junto con normalizarse en virtud de motivaciones esencialmente disruptivas y violentas, se utiliza metonímicamente para deslegitimar al movimiento estudiantil en su conjunto. Por lo tanto, se recontextualizan sus acciones y motivaciones a través de una narrativa multimodal en la que la desobediencia y el desorden civil se evalúan negativamente, exigiendo a la sociedad su neutralización inmediata. De allí que la investigación periodística no se centre meramente en el movimiento estudiantil y los colectivos que lo conforman, sino que además cumpla con la finalidad más general de criminalizar las formas de organización y acción política juvenil.

Una investigación de estas características puede aportar antecedentes a los Estudios de Juventud en dos direcciones. Por un lado, se propone que el paradigma de los Estudios Críticos del Discurso (ECD) puede contribuir con un posicionamiento epistemológico en torno al lenguaje y su utilización en contextos de abuso de poder, en los que se define un ethos juvenil por parte de las elites políticas y mediáticas que se distinguen por sus alianzas económicas e ideológicas. Por otro lado, se dan a conocer modelos analíticos que ofrecen una descripción detallada de las estrategias que configuran ciertos discursos hegemónicos sobre los actores y las acciones juveniles, como es el caso de los medios de comunicación tradicionales y sus distintos formatos informativos. Estas aproximaciones teórico-metodológicas ayudan a dilucidar cómo se configuran, sostienen y reproducen las representaciones de los jóvenes encapuchados como sujetos de amenaza, desviación y subversión social, al tiempo que estimulan un trabajo interdisciplinar para deconstruir estos ejercicios de deslegitimación, poniendo a disposición evidencia lingüística y semiótica que puede operar como un interesante punto de partida.

\section{Lista de referencias}

Abric, J. C. (1996). Specific processes of social representations. Papers on Social Representations-Textes sur les Représentations Sociales, 5 (1), pp. 77-80.

Aguilera, Ó. (2008). Medios de comunicación en Chile, movimientos juveniles y políticas de la visibilidad. Comunicação, Mídia e Consumo, 5 (14), pp. 55-68.

Aguilera, Ó. (2010). Acción colectiva juvenil: de movidas y finalidades de adscripción. Revista Nómadas, (32), pp. 81-98. 
Antezana, L. (2007). Los jóvenes "en" los noticieros televisivos chilenos. Revista Latinoamericana de Ciencias de la Comunicación, (5), pp. 154-163.

Bellei, C. \& Cabalin, C. (2013). Chilean student movements: Sustained struggle to transform a market-oriented educational system. Current Issues in Comparative Education, 15 (2), pp. 108-123.

Bellei, C.; Cabalin, C.\& Orellana, V. (2014). The 2011 Chilean student movement against neoliberal education policies. Studies in Higher Education, 39 (3), pp. 426-440. Doi: 10.1080/03075079.2014.896179.

Benford, R. \& Snow, D. (2000). Framing processes and social movements: An overview and assessment. Annual Review of Sociology, 26, pp. 611-639. Doi: 10.1146/annurev.soc.26.1.611.

Boyle, M.; McCluskey, M.; McLeod, D. \& Stein, S. (2005). Newspaper and protest: An examination of protest coverage from 1960-1999. Journalism \& Mass Communication Quarterly, 82 (3), pp. 638653. Doi: 10.1177/107769900508200310.

Cabalin, C. (2012). Neoliberal education and student movements in Chile: Inequalities and malaise. Policy Futures in Education, 10 (2), pp. 219-228. Doi: 10.2304/ pfie.2012.10.2.219.

Cárdenas, C. (2011). (In)visibilización juvenil: acerca de las posibilidades de las y los jóvenes en la historia reciente del país. Revista Última Década, 19 (35), pp. 11-31. Doi: 10.4067/S0718-22362011000200002.

Cárdenas, C. (2012). ¿Dónde debe emplazar su ojo la historia? (In)visibilización de las y los jóvenes en discursos disciplinares que recuperan el pasado reciente chileno (1970-1990). Discurso \& Sociedad, 6 (2), pp. 283-313.

Cárdenas, C. (2014a). Jóvenes e (in) visibilización histórica: modos de representación ideológica de la juventud chilena en el pasado reciente (1970-1990). Signos, 47 (85), pp. 217-244. Doi: 10.4067/ S0718-09342014000200004.

Cárdenas, C. (2014b). Representación de la acción política de los estudiantes chilenos.
Movilización de significados en redes sociales. Revista Última Década, 22 (40), pp. 57-84. Doi: 10.4067/S071822362014000100004.

Cárdenas, C. (2016a). El movimiento estudiantil chileno (2006-2016) y el uso de la web social: nuevos repertorios de acción e interacción comunicativa. Revista Última Década, 24 (45), pp. 93-116. Doi: 10.4067/ S0718-22362016000200006.

Cárdenas, C. (2016b). Representación online del movimiento estudiantil chileno: reapropiación de noticias en Facebook. Estudios Filológicos, (58), pp. 25-49. Doi: 10.4067/S0071-17132016000200002.

Cárdenas, C. \& Pérez, C. (2016). The hooded student as a metaphor: Multimodal recontextualizations of the actions and motives of the Chilean student movement in a broadcast news report. 6th Critical Approaches to Discourse Analysis across Disciplines Conference (Cadaad). Universita' degli studi di Catania, Catania, Italia.

Cohen, S. (1972). Folk devils and moral panics: The creation of the Mods and Rockers. London: Routledge.

Cohen, S. (1973). Mods and Rockers: The inventory as manufactured news. En S. Cohen \& J. Young (eds.) The manufacture of news. Deviance social problems \& mass media, (pp. 263-279). London: Constable.

Cohen, S. \& Young, J. (1973). The manufacture of news. Deviance social problems \& mass media. London: Constable.

Condeza, R. (2005). La infancia y la adolescencia en primera plana. Cuadernos de Información, (18), pp. 140-147. Doi: 10.7764/cdi.18.154.

Del Valle, C.; Mayorga, J. \& Nitrihual, L. (2010). Prensa, justicia y producción narrativa del poder: Fundamentos teóricometodológicos para un estudio comparado del discurso. Convergencia, 17 (54), pp. 175-198.

Estay, L.; Castro, C.; Cayunao, C.; González, J.; González, S. \& Mancilla, Y. (2016). Análisis del discurso en medios de prensa chilenos sobre la detonación de la bomba 
del 8 de septiembre de 2014. Revista de Estudios Cualitativos, 2 (1), pp. 60-81.

Fairclough, N. (1995). Critical discourse analysis: The critical study of language. London, New York: Longman.

Fairclough, N. (2005). Critical discourse analysis in transdisciplinary research. En R. Wodak \& P. Chilton (eds.) A new agenda in (critical) discourse analysis: Theory, methodology and interdisciplinarity, (pp. 53-70). Amsterdam, Philadelphia: John Benjamins.

Fairclough, N.; Mulderrig, J. \& Wodak, R. (2011). Critical discourse analysis. En T. Van Dijk (ed.) Discourse studies. A multidisciplinary introduction, (pp. 357378). London: Sage.

Feng, D. \& Espindola, E. (2013). Integrating systemic functional and cognitive approaches to multimodal discourse analysis. Ilha do Desterro, (64), pp. 85-110. Doi: 10.5007/2175-8026.2013n64p85.

Feng, D. \& O'Halloran, K. L. (2013a). The visual representation of metaphor. Review of Cognitive Linguistics, 11 (2), pp. 320335. Doi: 10.1075/rcl.11.2.07fen.

Feng, D. \& O'Halloran, K. L. (2013b). The multimodal representation of emotion in film: Integrating cognitive and semiotic approaches. Semiotica, (197), pp. 79-100. Doi: 10.1515/sem-2013-0082.

Feng, D. \& Qi, Y. (2014). Emotion prosody and viewer engagement in film narrative: A social semiotic approach. Narrative Inquiry, 24 (2), pp. 347-367. Doi: 10.1075/ ni.24.2.09fen.

Gamson, W. (1989). The strategy of social protest. Sociological Forum, 4 (3), pp. 455-467. Doi: 10.2307/2148303.

Gascón, F. (2016). Actores, movimientos sociales y producción discursiva. Tentativas en torno a una epistemografía de la presencia. Altre Modernità. Rivista di Studi Letterari e Culturari, Numero Speciale: Nuevos movimientos sociales. Política y derecho a la educación, pp. 176200. Doi: 10.13130/2035-7680/7059.

Halliday, M. A. K. \& Matthiessen, C. (2014). Halliday's Introduction to Functional Grammar. London/New York: Routledge.
Jodelet, D. (1985). La representación social: Fenómenos, concepto y teoría. En S. Moscovici (ed.), Psicología Social, II. Pensamiento y vida social. Psicología social y problemas sociales, (pp. 469-494). Barcelona: Paidós.

Klandermans, B. \& Goslinga, S. (1999). Discurso de los medios, publicidad de los movimientos y la creación de marcos para la acción colectiva: ejercicios teóricos y empíricos sobre la construcción de significados. En D. McAdam, J. McCarthy \& M. Zald (eds.) Movimientos sociales: perspectivas comparadas, (pp. 442-474). Madrid: Itsmo.

Lasswell, H. (1927). Propaganda technique in the world war. New York: MIT Press.

Maletzke, G. (1964). Psicología de la comunicación colectiva. Quito: Ciespal.

Martínez, C. (2015). El delito de colocación, envío, activación y detonación de artefacto explosivo en la Ley Antiterrorista: análisis del tipo penal y su diferenciación con otros delitos similares en la legislación chilena. Memoria para optar al Grado de Licenciado en Ciencias Jurídicas y Sociales, Pontificia Universidad Católica de Chile, Santiago de Chile, Chile.

McAdam, D.; McCarthy, J. \& Zald, M. (1999). Oportunidades, estructuras de movilización $\mathrm{y}$ procesos enmarcadores: hacia una perspectiva sintética y comparada de los movimientos sociales. En D. McAdam; J. McCarthy \& M. Zald (eds.) Movimientos sociales: perspectivas comparadas, (pp. 21-46). Madrid: Istmo.

McCombs, M. \& Shaw, D. (1972). The agendasetting function of mass media. Public Opinion Quarterly, 36 (2), pp. 176-187. Doi: 10.1086/267990.

McLeod, D. (2007). News coverage and social protest: How the media's protest paradigm exacerbates social conflict. Journal of Dispute Resolution, (1), pp. 185-194.

Moscovici, S. (1985). Introducción: El campo de la psicología social. En S. Moscovici (ed.) Psicología Social, I. Influencia y cambio de actitudes. Individuos y grupos, (pp. 17-37). Barcelona: Paidós. 
Muñoz, V.; Durán, C. \& Thayer, E. (2014). Los jóvenes populares urbanos frente a la prensa escrita y digital: distorsiones, identificaciones, distancias y silencios. Revista Última Década, 22 (41), pp. 89-123. Doi: 10.4067/S0718-22362014000200005.

Murdock, G. (1973). Political deviance: The press presentation of a militant mass demonstration. En S. Cohen \& J. Young (eds.) The manufacture of news. Deviance social problems \& mass media, (pp. 206225). London: Constable.

Pérez, C. (2012). The Chilean student movement and the media: A comparative analysis on the linguistic representation of the 04 August 2011 manifestation in right-wing and left-wing newspapers. Logos: Revista de Lingüistica, Filosofia y Literatura, 22 (2), pp. 4-26.

Pérez, C. (2016). La representación visual del movimiento estudiantil chileno en la prensa establecida y alternativa nacional: un análisis multimodal. Revista Austral de Ciencias Sociales, (30), pp. 5-26.

Portillo, M.; Urteaga, M.; González, Y.; Aguilera, Ó. \& Feixa, C. (2012). De la generación X a la generación @. Trazos transicionales e identidades juveniles en América Latina. Revista Última Década, 20 (37), pp. 137-174. Doi: 10.4067/S071822362012000200007.

Santibáñez, M. E. (2015). Investigación por atentado en metro Escuela Militar entra en su etapa final. Derecho UC [online]. Recuperado de: http://derecho.uc.cl/ Derecho-UC-en-los-medios/profesoramaria-elena-santibanez-investigacion-poratentado-en-metro-escuela-militar-entraen-su-etapa-final.html

Snow, D. (2004). Framing processes, ideology, and discursive fields. En D. Snow; S. Soule \& H. Kriesi (eds.) The Blackwell Companion to Social Movements, (pp. 380-412). Oxford: Blackwell Publishing.

Snow, D.; Rochford, B.; Worden, S. \& Benford, R. (1989). Frame alignment processes, micromobilization, and movement participation. American Sociological Review, 51 (4), pp. 464-481.
Sunkel, G.\& Geoffroy,E. (2001).Concentración económica de los medios de comunicación. Santiago de Chile: LOM.

Tamayo, T. (2012). Caso Bombas. La explosión en la Fiscalía Sur. Santiago de Chile: LOM.

Tarrow, S. (2011). El poder en movimiento. Los movimientos sociales, la acción colectiva y la política. Madrid: Alianza.

Titscher, S.; Meyer, M.; Wodak, R. \& Vetter, E. (2000). Methods of text and discourse analysis. London: Sage.

Van Dijk, T. (1985). Discourse and communication. Berlin/New York: Walter de Gruyter.

Van Dijk, T. (1988). News analysis. London/ New York: Routledge.

Van Dijk, T. (1990). La noticia como discurso. Barcelona: Paidós.

Van Dijk, T. (1999). Ideología. Barcelona: Gedisa.

Van Dijk, T. (2009). Discurso y poder. Barcelona: Gedisa.

Van Dijk, T. (2011a). Sociedad y discurso. Barcelona: Gedisa.

Van Dijk, T. (2011b). Introduction: The study of discourse. En T. Van Dijk (ed.) Discourse studies. A multidisciplinary introduction, (pp. 1-34). London: Sage.

Van Dijk, T. (2012). Discurso y contexto. Barcelona: Gedisa.

Van Dijk, T. (2015). Critical discourse analysis. En D. Tannen; H. Hamilton \& D. Schiffrin (eds.) The handbook of discourse analysis, (pp. 466-485). Chichester: John Wiley \& Sons.

Van Dijk, T. (2016). Discurso y conocimiento. Barcelona: Gedisa.

Van Leeuwen, T. (2007). Legitimation in discourse and communication. Discourse \& Communication, 1 (1), pp. 91-112. Doi: 10.1177/1750481307071986.

Van Leeuwen, T. (2008). Discourse and practice: New tools for critical discourse analysis. Oxford: Oxford University Press.

Villegas, M. (2016). El terrorismo en la Constitución chilena. Revista de Derecho, XXIX (2), pp. 295-319. Doi: 10.4067/ S0718-09502016000200014. 
Weiss, G. \& Wodak, R. (2003). Introduction: Theory, interdisciplinarity and critical discourse analysis. En G. Weiss \& R. Wodak (eds.) Critical discourse analysis: Theory and interdisciplinarity, (pp. 1-32). Hampshire/New York: Palgrave Macmillan.

Wodak, R. \& Meyer, M. (2009). Methods of critical discourse analysis. London: Sage.

Wodak, R. (2013). Critical discourse analysisChallenges and perspectives. En R. Wodak (ed.) Critical Discourse Analysis I, (pp. xix-xli). London: Sage.

Yez, L. (2007). De maleante a revolucionario. Cuadernos de Información, (20), pp. 3743. 